\title{
Analysis of the Illustrations by Ivan Yakovlevich Bilibin (1876-1942) to Russian Fairy Tales
}

\begin{abstract}
The article analyzes the works performed by Ivan Yakovlevich Bilibin, a Russian artist, whose artistic ascent took place at the turn of the 20th century while Russian intellectuals were actively engaged in identifying the specific features of Russian cultural identity. The article also provides a short description of the works by Ivan Yakovlevich Bilibin in the context of visual arts theory and performance. The analysis of the artist's works brings to light visual images of the Russian cultural identity that they contain and help to construct this identity in a specific way. Based on the philosophical, artistic, and culturological analysis of the two illustrations "Koschei the Deathless" (1901) and "Vasilisa the Beautiful at Baba Yaga's Hut" (1899), the craftsman's representative works on Russian fairy tales, an ethnocultural world view model was constructed in the works by Ivan Yakovlevich Bilibin. The artistically displayed Russian cultural features visualized by the artist as "an emphasis on chthonic forces", "the quiet acceptance of death", "the coexistence of opposite forces, including life and death", "femininity", "the three-part structure of the world", "the relativity and transparency of boundaries", and "the forest as a model of the Russian world" have been specified. By resorting to folklore plots, the famous Russian artist Ivan Yakovlevich Bilibin brought into light in his visual illustrations the archetypes that exert the greatest influence on the formation of ideas about the Russian world view, Russian people, and Russian cultural features.
\end{abstract}

Keywords: Folk Art, Ivan Y. Bilibin, Russian Art of XX-XXI centuries.

\section{INTRODUCTION}

Ivan Yakovlevich Bilibin, a late 19th/early 20th century Russian artist, was a member of the World of Art Association (Mir Iskusstva), created book illustrations and designed theatrical scenery and stage costumes. He is mostly known to a wide audience for his illustrations to A.S. Pushkin's fairy tales, Russian fairy tales and traditional heroic poems, the illustrations that are the basis of his artwork. Storybooks accompanied with Bilibin's illustrations are published to this day.

However, there are few scientific papers dedicated to the Russian artist's life and works. The following Russian researchers are notable for their work devoted to the artist: S.V. Golynets [1] (a compiler of albums, letters and memoirs); O. S. Semenov [2] (an author of accompanying texts to albums containing reproductions and describing the master's biography, his style and creative periods). Western researchers mainly consider the artwork by I. Y. Bilibin in the context of analysis of the Russian art of the late 19th and early 20th centuries. Great attention is paid to the creative activities of the different artistic associations taking place during the period under consideration; the Silver Age in the Russian culture and art is also thoroughly studied. For example, O. Ronen [3] considers the term "Silver Age" and the importance of this phenomenon in the modern Russian culture and, therefore, studies the work of the prominent creative figures belonging to the same period. P. Stupples [4] in his article studies the artwork by the Abramtsevo Colony artists. J. E. Bowlt [5] is an author of a vast paper dedicated to the World of Art Movement (Mir Iskusstva). T. Shah [6] in his study of the Russian identity and modernization and westernization processes in the 19th century uses the Russian art as an analytical tool in order to identify the features of ethnic national identities. 
The active work of the artists visualizing the Russian history, Russian fairy tales, traditional heroic poems and special features of the national ideology and identities is clearly attributable to the turn of the 19th and 20th centuries. S.V. Golynets [1] considers this period in the culture from the perspective mentioned above and describes the general situation in the artistic field through the activities undertaken by Sergei Diaghilev. N. P. Koptseva and N. M. Libakova [7] consider the paintings related to the turn of the centuries as visual philosophical texts, reveal, through the examples of women's images in the works by B. Kustodiev, V. Borisov-Musatov, F. Malyavin, artistic concepts relatable to the philosophical ideas of the epoch and reflecting the formation processes of the Russian identity.

Considering the pieces of art as objects not just containing visual images of the Russian cultural identity, but also forming this very identity in a specific way is explained and confirmed by a number of studies carried out by N. P. Koptseva [7.8], N. N. Seredkina [8], N. M. Libakova [7], A. V. Kistova [9] and intended for understanding the mechanisms of formation of this or that type of identity.

S. V. Golynets notes in his article that "the unity of an artistic interest in the art of Ancient Rus' and a scientific one identifies the features of the Neorussian style peculiar to the World of Art members: Bilibin, Roerich and Stelletskii who joined the movement later. Being more rational in their national and romantic strivings than their Moscow colleagues, these artists tried to create a quasi-real, quasi-fictional world on the basis of archaeologically and ethnographically authentic details" [1], which indicates that the Russian world's images peculiar to their artwork are modeled in a conscious and rational way.

I. Y. Bilibin thoroughly studied the Russian artworks, particularly those made in the 17th century, and tried to be accurate in depicting everyday household details, costumes and architecture. But he was not just an imitator of the old Russian style. I. Y. Bilibin was keen to create a new Russian style and reconsider the national artistic heritage and traditions in his artwork. The artist in his article "The Folk Art of the Russian North" writes: "So now nationalist artists are faced with a task of colossal difficulty: using this rich and ancient heritage, they must create something new and serious that logically follows from what has survived.... We shall try to let nothing slip from our attention. And perhaps, under the influence of this passion for bygone beauty, there may even be created, at last, a new, completely individual Russian style with nothing of tawdriness about it. And the stronger this desire is, the more data are for the creation of this new Russian style" [10]. In the same article, the author describes the strategy to be followed by artists and everyone who wishes to create a new Russian style. Collecting and studying folk art works can help to create a new real Russian style. Studying Russian ornaments should be purely based on originals, which should be massively promoted in all art institutions. I. Y. Bilibin explains the role of the artist as follows: "Artists are interpreters of those beauties hidden in many folk pieces, those ones not catching the eye at first glance" [10]. The extracts from the artist's article make it clear that the problem of formation of the Russian culture's images is one of the tasks he had to face in creating his graphic works.

\section{MATERIALS AND METHODS}

The works selected for the philosophical, art and culturological analysis are representatives of the artist's style (known as "the Bilibin style") and are watercolors made in the book illustration genre. The distinguishing features of the artist's style are clear contour lines that help to create compositions in great detail, with further decoration with watercolors. All volume elements are represented as flats for ornaments.

The study relies on the method of philosophical, art and culturological analysis developed by V. I. Zhukovsky, N. P. Koptseva [11], as well as on general scientific research methods. The effectiveness of this method in studying book illustrations and 
the actualization of selection of book graphics for the purpose of identifying specific features of ethnic cultural images are presented in the article by M. A. Kolesnik [12].

In addition, within the analysis of the fairy stories visualized by I. Y. Bilibin, the authors rely on the findings made in the sociological imagination sphere [13], taking into consideration the universal nature of mythological and fairy images.

\section{RESULTS AND DISCUSSION}

The illustration "Koschei the Deathless" (1901) to the Russian fairy tale "Marya Morevna" is made on a sheet of horizontal format. Like most of Bilibin's works, it is decorated with a drawn frame including solar signs in its lower and upper parts and having alternating plant elements: fir trees and flowers on both left and right sides.

At first glance, there are many questions related to the figures of the horseman and the steed: why is the horseman completely naked? Why does he hold the sword in his hand? Against whom is he going to fight? This gray-haired figure is presented not as a feeble old man, but a rather strong and powerful warrior. It is also obvious that the figure is a concentration of force and there is no association with weakness. He stretches out his right hand with the sword that occupies a considerable space in the whole picture. Its silhouette is highlighted against a clear sky background. Its accurate form and sharp line contrast with surroundings.

The horseman and the steed bear a clear resemblance to a centaur. The steed itself bears a certain similarity to the horseman: its gray-haired mane, old age, strength and energy; it is free from any "shackles", it has no reins, saddle or defensive features.

Analyzing the natural space provides the following results: the whole space, or even the whole world, is a forest that is also involved in the presented event, being one of its heroes. What can we say about the sky? First of all, it has rare clouds, and, secondly, it is impossible to say exactly whether the sunset or dawn is represented in the picture. Such light may be both in the morning and in the evening. That is, the time of the event is uncertain. If we take a careful look at the shape of the clouds, it is possible to note that it reminds of figures of moving riders, three in number to be precise, and the cloud at the top is recognized as a figure of some fantastic creature similar to a dragon or a snake (its beak, head, noticeable eye, wing, paw and long tail).

The sword is the only element that may be related to an object of the human world. The horseman holds the sword in order to defeat and destroy, but not to defend himself.

The use of this fairy tale plot illustrated by I. Y. Bilibin helps to reveal some aspects of the horseman's image. On the one hand, the text of the fairy tale conveys an idea of unity between the horseman and the steed as they play the same game, as shown in I. Y. Bilibin's work. On the other hand, the artist suggests his own interpretation of Koschei the Deathless: an embodiment of chthonic and wild forces acting in favor of nature, a kind of martial male principle.

The word "Koschei/Kaschei", if etymologically analyzed, allows us to make certain conclusions. The word has several meanings, one of which is a slave, prisoner, servant; it also means a lord, derived from the words "kosch", "kost" (bone, backbone), a basis or a root of a family, the oldest person in a family, a person who becomes a lord. Also, the word "kosh" may be attributable to the word "koshelek" (purse), which means a keeper of all possible goods and advantages, including immortality.

The visual image of Koschei in the picture by I. Y. Bilibin appears in the aspect of a lord, elder family member, leader. It also has a protective function, therefore all the natural forces follow and obey the horseman. But who is an invisible enemy of Koschei and nature? The answer to this question is given in the interpretation of Marya Morevna's image, a Russian fairy tale heroine. For example, I. A. Birich suggests an interesting linguistic interpretation of this image, different from many of those suggested by researchers: "The other half of Veles, a Slavic god, is Marya Morevna, a Russian goddess of death. Since then, all the words that have the roots of "mor-mer" 
bear a sign of uncertainty, risk and catastrophe: "smert" (death), "umeret" (to die), "mor" (pestilence), "moroz" (cold), "morosit": (to drizzle), etc." [14]. Thus, Koschei, being on the side of the natural forces, fights against the forces of darkness and death.

The artist interprets the image of Koschei in a rather positive way, in contrast to a generally accepted stereotype of his dark and evil character, and somehow restores the necessity of overwhelming and wild natural forces in the system of the world.

As far as a place of a human being in the artist's visualized world structure is concerned, it is clearly considered as a forest space. Therefore, it is possible to say that in this case the forest acts as a model of the earth and the Russian world. This world is characterized as a boundary and dangerous space because it has supernatural forces, and at the same time it is associated with the antiquity of the Russian people and, therefore, understood as a native one.

The second work: "Vasilisa the Beautiful at the Hut of Baba Yaga". The illustration to the fairy tale "Vasilisa the Beautiful" (1899). The illustration is made on a sheet of vertical format. In the center of the picture there is a female figure against the background of a space full of different decorative elements and objects. This space is framed with decorative ornaments.

There is a girl who makes a step forward, her right arm is stretched and taken back as if she walks with hesitation and by touch. In her left hand she holds a stick and a skull is stuck on the end of the stick. The skull is notable for luminous eye sockets. Her head and eyes face the same direction as the light coming from the eye sockets of the skull. Her hair is blond with a long flowing braid resting on her left shoulder. She wears a long blue sarafan and a white long sleeved apron over it, the lower part of the dress is smartly decorated with embroidery representing geometric, floral and zoomorphic ornaments (including birds and flowers). The smartness of her dress is also highlighted with several strings of beads on her neck. She wears bast shoes and her left foot that makes the first step is clearly seen. It is also clear that the girl is gentle, her movements are smooth and calm. There is no hurry, but carefulness. It is also confirmed by the fact that her hair is not messed up and her costume is in good condition.

The foreground includes a grassed meadow, fir trees and shrubs. The meadow is flecked with daisies, yellow flowers and mushrooms growing on and around a rotten stump. Behind the girl there is a broken birch tree indicating a border between the meadow where the girl is and the dense forest that separates a farther space where we can see a hut and a fence made of bones and skulls. Behind the birch tree there are thick ferns and fir trees, fragments of trees that form a sort of wooden fence are also clearly seen. The three thin tree trunks are tilted so that they form an arch over the girl's head and mark an entrance to the space in the background. Behind the trees there is the fence made of bones, with long poles and human skulls notable for luminous eye sockets.

Almost the whole space in the background is occupied by the wooden hut whose windows are richly decorated with carved ornaments. Light can be seen in its opened window. And only after taking a careful look at the hut, it is possible to see that it is based on a long-clawed hen's foot. In addition, between the trees we can see a part of the hut's roof, a so-called "bargeboard" (a carved board presented with carved ornaments and having three decorative carved elements similar to phalanges).

The author fixes a mismatch between the calm girl and frightening attributes (bones, skulls, dense forest), between the ordinary and the fantastic (the hut on the hen's feet), the alive and the dead (the girl and the human-like hut, and the signs of death: bones and skulls).

The only warm light is in the hut's window. The light coming from the skulls' eye sockets has a clear otherworldly, supernatural and fantastic nature. It is also uncertain what illuminates the meadow in the foreground, it is filled with light, but what is the source of the light, where does the light in the night forest come from? The light is described as a mystical and supernatural thing that is related to the other world, it is a dead and lifeless light. 
The presented objects and figures are grouped according to the principle of belonging to this or that specific world: the human world (the girl, her dress, the hut, its decorative elements), the natural world (the trees, mushrooms, flowers) or the other world (the skulls, the hut on hen's feet). It is necessary to understand how these three worlds are interrelated. If we return to the analysis of the girl's figure and take a careful look, it is noticeable that the claw on the hut's foot purportedly catches and holds the girl's sleeve, which is confirmed by the folds of her sleeve. And the girl's figure is not as simple as it seems at first glance. The viewer sees only one foot making a step forward, while the second one is buried in the grass, becoming more similar to a beast's paw, and the girl remarkably relies on this second foot. Therefore, the girl is connected with the natural and animal forces, she comes out of their world, but faces the other inhuman world since she follows the light from the eye sockets of the skull. The hut is notable for its anthropomorphic features: although hen's, but still the feet, the window in the form of an eye, the roof's decorative element (known as "bargeboard") resembles a hand, etc.

The analysis of the heroine's dress plays a very important role in understanding the picture's idea. It should be noted that I. Y. Bilibin had a good knowledge of Russian costumes, symbols and their meanings. The picture shows the girl dressed in the sarafan, but the top element worn over the dress is of special interest. The fact is that this kind of apron is a part of "maiden's tragic costume" associated with some changes in the girl's social status, with the beginning of a new period in her life. The white color in the Russian tradition is associated with death, when used in the dress it means the mourning over the past (a bride's white dress). That is, in other words, we have the girl who dies in one capacity, but has to find a new life in another. In this context death is not perceived as something terrible, but it is a necessary stage through which a person has to pass. The ornament on the apron represents life-affirming symbols: birds pointing to the heaven (a spiritual space) and floral elements (a traditional motif of the world tree).

When comparing the fairy tale's text and the picture made by the artist, we can find some inconsistencies: Baba Yaga is absent as an active character, or her presence is implicit. V. Y. Propp [15] considers different types of this fabulous character and her functions. I. Y. Bilibin's work depicts an aspect of Baba Yaga as a donor who provides the girl with a magical object. V. Y. Propp draws attention to the fact that Baba Yaga is associated not only with death, but also with ancient social life, including rites of initiation taking place in the forest in the strictest privacy. Baba Yaga's function is to protect and defend Vasilisa against the spirit world's destructive forces, that is why the hut looks like a home front that does not allow the girl to get lost in the world of thin and uncertain borders.

Vasilisa presented in the picture is a bearer of secret and sacred knowledge. Vasilisa is the only living creature, a representative of the human world, a creature belonging to the reality and the visible and tangible world. The trees, flowers and grass indicate the world of nature, known as the world of Prav' in the Slavic mythology, that is ruled by Rod ("birth", "origin", "kin"), a Slavic god and creator of all life and existence. And all the death-related signs point to the third world, Nav', invisible to humans and inhabited by spirits, the one threatening people with risks and dangers. In the work the three levels of the universe are merged into one single entity where it is difficult to understand where one world ends and another begins.

If we return to Russian fairy tales, the artist I. Y. Bilibin forms an original idea about the world structure and human activities. The work visualizes the subtlety of the worlds' borders being transformed into one another and a female, friendly, internally spiritual and illuminated approach to learning the world and committing actions, the one typical for the Russian culture. Also, it visualizes an ability to be flexible and firm (typical female characteristics). All secrets and mysteries of the world are revealed only through knowledge of good and evil, light and darkness in their unbreakable unity. 


\section{CONCLUSIONS}

The conducted study allows us to make several conclusions characterizing the special features of visualization of Russian fairy tales in the artwork by I. Y. Bilibin.

By using fairy tale plots, the artist reveals those archetypes that have the greatest influence on forming the ideas of what is Russian, who are Russians and what are Russian cultural aspects. For instance, Bilibin's illustrations visualize a person's ability to go beyond the obvious and the ordinary, the ability that promotes the vision of connection of such phenomena in their single unity. The artist also visualizes ancient ideas about the three-part world structure that are revealed in his works not only in their compositional form, but also in the signs he uses (decorative ornaments and elements).

The fairy tale images presented in the works by I. Y. Bilibin are generally characterized by the female principle that has a positive sense. The presence of dark and light forces is described in their unbreakable unity, but it is possible to differentiate one from another. Death is regarded as a stage followed by a new birth, which reflects the integration of death into the general world view of Russian people.

According to the philosophical, art and culturological analysis of the artist's works, the following special features of the Russian cultural identity have been identified: "reliance on chthonic forces", "relatively calm acceptance of death", "coexistence of opposite forces, including life and death", "three-part world structure", "uncertainty and transparency of borders", "forest as a model of the Russian world", "unity of man and nature", "spirituality of the surrounding world", "contemplation", "femininity of Russian images".

\section{REFERENCES}

[1] Golynets, S. V. Sergei Diaghilev and the national romantic quest in Russian art, News of the Ural state University, vol. 33. pp. 211-215, 2004.

[2] Semenov, O. Ivan Bilibin: the story of the artist-storyteller, Moscow, P.87, 1996.

[3] Ronen Omry. The Fallacy Of The Silver Age. - Routledge, USA, Russia, 139 p., 2013.

[4] Stupples P. Abramtsevo: Resisting and Accepting Cultural Translation, New Zealand Slavonic Journal, vol. 45, No 1, pp. 71-90, 2011.

[5] Bowlt J. E. Synthesism and Symbolism: the Russian «World of Art» Movement, Forum for Modern Language Studies, Oxford University Press, vol. 9, No 1, p. 35, 1973.

[6] Shah T. Modernization as Westernization? The geopolitical consequences of ethnonationalism analyzed through Russian Art, Nationalities Papers, vol. 41, No 5, pp. 744$760,2013$.

[7] Koptzeva, N.P., Libakova, N.M. Native culture of the $19^{\text {th }}-20^{\text {th }}$ centures in search after truth of real human being in Vladimir Solovyov's philosophy of the universal unity and works of art in the Russian painting, Journal of Siberian Federal University. Series: Humanitarian Sciences, Krasnoyarsk, vol. 2, No1, pp. 67-83, 2009.

[8] Koptseva, N.P., Seredkina N. N. Constructing of a positive ethnic identity in a multicultural system, Krasnoyarsk, 184 p., 2013.

[9] Kistova A.V., Koptseva N. P. Constructing of ethno-cultural and national identity as a philosophical problem, Philosophy and culture, Moscow, No 1, pp. 12-19, 2015.

[10] Bilibin I. Y. Folk art of the Russian North, The World of art, Russia, Vol. 12, pp. 304-318, 1910.

[11] Zhukovskiy V. I., Koptseva N.P. Proposition of the theory of art. Krasnoyarsk, 257 p., 2004.

[12] Kolesnik, M.A. Decoration of children's literature of the indigenous peoples of the North Siberia and the Far East, Journal of Siberian Federal University. Series: Humanitarian Sciences, Krasnoyarsk, vol. 9, No 12, pp. 2044 - 2059, 2016. 
[13] Kolesnik, M.A. Imaginary worlds as a subject of «Eranos» intellectual group's research in the 30-80S of the XX century, Journal of Siberian Federal University. Series: Humanitarian Sciences, Krasnoyarsk, vol. 9, No 1, pp. 79 - 90, 2016.

[14] Birich I. A. Modern Russian language - the Keeper of the ancient worldview (the main archetypes of Russian mentality), Philosophy. Political Science, Moscow, No. 1, p. 4, 2009.

[15] Propp, V. Y. Historical roots of a fairy tale, Moscow, 333 p., 2000. 